\title{
Arquivo e Testemunho da Psicologia como Ciência e Profissão
}

Archive and Testimony as a Science and Profession

Archivo Y Testimonio De La Psicología Como

Ciencia Y Profesión

Tania Mara

Galli Fonseca

Universidade

Federal do Rio

Grande do Sul
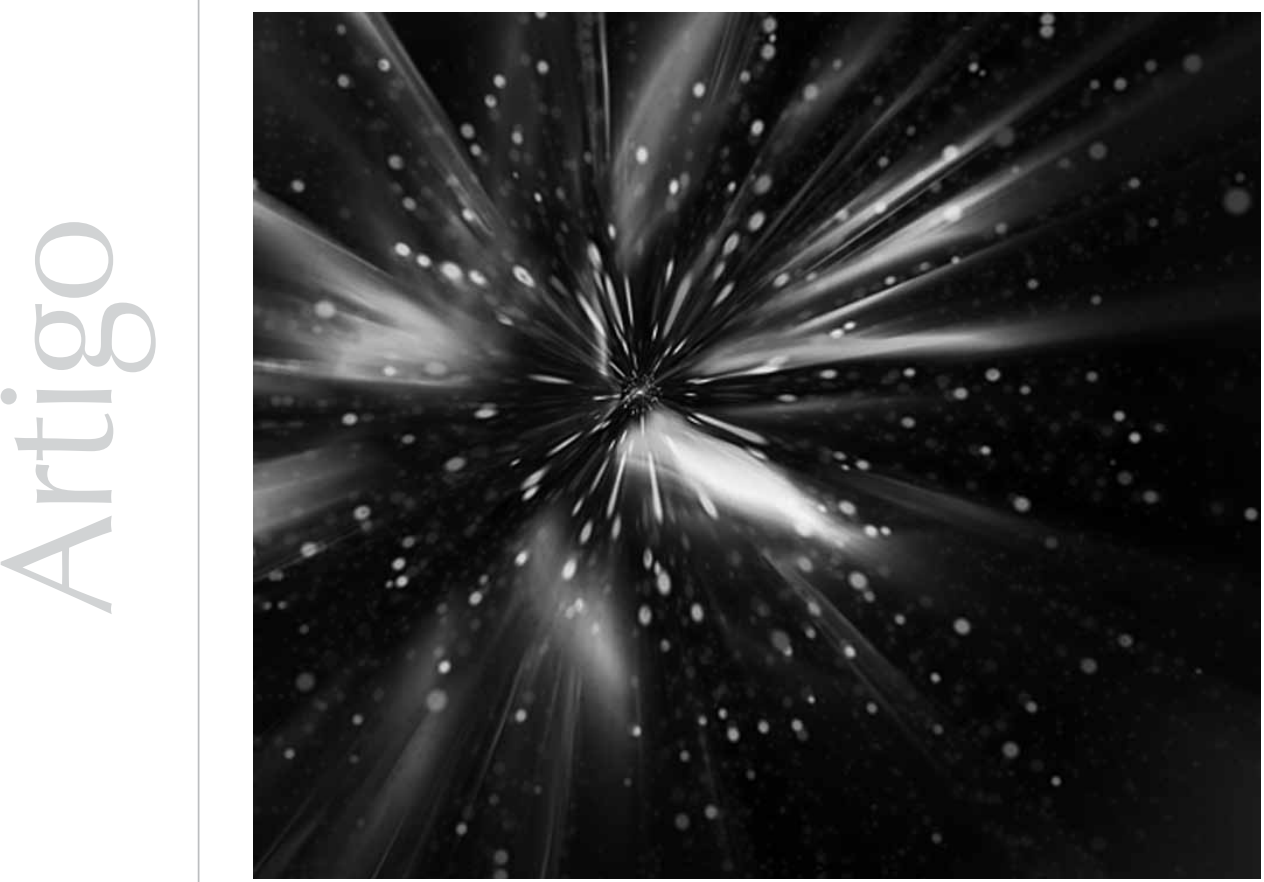
Resumo: Neste texto, abordamos a Mostra Nacional de Práticas em Psicologia a partir dos conceitos de arquivo e testemunho. Considerando-a como arquivo coletivo, a Mostra pode ser vista como o plano comum de uma multidão enunciadora que, como testemunha, enuncia aquilo que tem sido e em que está se tornando a Psicologia como ciência e profissão. A questão dos diálogos da Psicologia com outros saberes é mostrada como relevante aos devires de nossa ciência, uma vez considerarmos que dialogar com outros domínios das ciências, das artes e da filosofia refere-se a um modo de produzir aberturas no atual arquivo de saberes que produzimos em direção a outros e novos futuros possíveis.

Palavras-chave: Historia da Psicologia - Brasil. Ciência. Memória. Tempo.

Abstract: In this text we approach the National Exhibition of Psychological Practices from de concepts of archive and testimony. Considering the Exhibition as a collective archive it can be seen as a common ground of a multitude of enunciation that, as a testimony, expresses what have been and what Psychology is becoming as a science and as a profession. The dialogue between Psychology and other knowledge is shown as relevant for the transformations of our science, as we consider that the dialogue with other domains of science, arts and philosophy produces overtures in the present archive of knowledge and points to the direction of new possible futures.

Keywords: History of Psychology- Brasil. Science. Memory. Time.

Resumen: En este texto, abordamos la Muestra Nacional de Prácticas en Psicología a partir de los conceptos de archivo y testimonio. Considerándola como archivo colectivo, la Muestra puede ser vista como el plan común de una multitud enunciadora que, como testimonio, enuncia aquello que ha sido y en qué se está tornando la Psicología como ciencia y profesión. La cuestión de los diálogos de la Psicología con otros saberes es mostrada como relevante a los devenires de nuestra ciencia, una vez que consideramos que dialogar con otros dominios de las ciencias, de las artes y de la filosofía se refiere a un modo de producir aberturas en el actual archivo de saberes que producimos en dirección a otros y nuevos futuros posibles.

Palabras clave: História de la Psicologia (Brasil). Memoria y devenires

Certamente precisamos da história, mas não como o passeante mimado no jardim do saber (...): precisamos dela para a vida e para a ação, não para o abandono confortável da vida ou da ação ou mesmo para o embelezamento da vida egoísta e da ação covarde e ruim. Somente na medida em que a história serve à vida queremos servi-la.

(Nietzsche, 2003, p. 5)

\section{A Mostra Nacional como arquivo e testemunho}

A data é de aniversário. Reúnem-se, na grande Mostra Nacional, aqueles que ocupam o território da Psicologia como ciência e profissão, aniversário institucional transformado em um fabuloso banquete de oferendas que serão expostas para fins de compartilhamento e, por que não, para que se possa também visualizar o tamanho e a grandeza do que tem sido produzido. Todos acorrem ao evento sabendo serem simultaneamente instrumentos e efeitos, criadores e criaturas da instituição que os sustenta. Ocupando o lado instituinte oferecido pela instituição, sabem que se trata de uma data diante da qual se pode vir a observar não apenas o passado já vivido e experimentado, como tempo decorrido em linha reta, cronologicamente desenhado em uma evolução em direção ao um progresso ou a um declínio. O tempo comemorado nesta Mostra Comemorativa não pode ser aquele acostumado a erguer heróis, a cultuar 
Egos e a embalar-se em rituais narcísicos e individualistas. O que conta, nesta festa, é o arquivo, regido por um tempo sem medida, criador de uma evolução feita por multidões, por grandes e pequenos gestos sobretudo e sempre marcados pela capacidade de pensar para além das origens e dos saberes dados, para além do concreto já formalizado, para além do humano que nos confronta. Todos os que o produziram não podem, de forma alguma, ser chamados de autores. Estiveram imersos nos complexos agenciamentos do acontecimento discursivo que se efetua fora da consciência de um indivíduo e que, antes, o absorve e o torna seu efeito. Quando quisermos ultrapassar o arquivo de sua materialidade acumulada, de seu presente aí exposto aos nossos olhos e ouvidos, precisamos adentrar no anonimato de um murmúrio para dele extrair a polifonia daqueles que ocupam/ocuparam a funçãoautor. $\mathrm{E}$, então, em tal perspectiva, já não nos faz sentido perguntar "quem fala"? pois a consideramos um falso problema. É sempre um sujeito que fala, e, ao falar, fala a partir de enunciados discursivos. Da mesma forma, os enunciados tornam-se possíveis pelas condições de visibilidade e de dizibilidade de um dado tempo histórico, evidenciando que toda a História "não corresponde apenas ao arquivo em seu sentido restrito - ou seja, ao depósito que cataloga os traços do já dito para consigná-los à memória futura, nem à babélica biblioteca que acolhe o pó dos enunciados a fim de permitir a sua ressurreição sob o olhar do historiador" (Agamben, 2008, 145). O arquivo, que, segundo Foucault (como citado por Deleuze 1998, p. 171), corresponde ao plano de enunciação, ao "sistema geral da formação e transformação dos enunciados", também sofre seu mal, podendo ser visto como a massa do não semântico, a margem obscura que circunda e limita a tomada de palavra. É assim que nos autorizamos a perceber que a Mostra Nacional como arquivo se situa no "não-dito e no dizível inscrito em cada dito, pelo fato de ter sido enunciado, o fragmento de memória que se esquece toda vez no ato de dizer eu" (Agamben, 2008, 145). Focá-la a partir da noção de arquivo significa primeiro reconhecê-la como um acúmulo relacionado ao sistema de relações entre o dito e o não dito, entre a função enunciativa e o discurso sobre o qual se projeta, entre o fora e o dentro da linguagem. A Mostra, de onde podemos desenterrar os artefatos e os enunciados que os tornaram possíveis, revela-se como solo arqueológico, denotando, para os atentos, as pontas de um tempo ontológico e produtor. Arqueologia e genealogia encontram-se aí reunidas em um ponto para onde convergem o já aí e o como foi possível que estivesse aí. No arquivo da Mostra, encontram-se os saberes até então possíveis que foram até agora exteriorizados e objetivados, mas também encontram-se as lacunas do que ainda resta a dizer. Igualmente, nela não encontramos vestígios de autores, pois "se uma proposição, uma frase, um conjunto de signos podem ser chamados de 'enunciados', não é porque houve, de fato, um dia, alguém que os tenha proferido ou tenha deixado em algum lugar sua marca provisória, mas sim, porque, com eles, pode ser estabelecida a posição de sujeito.

Descrever uma formulação como enunciado não consiste em analisar as relações entre o autor e o que é dito (ou se quis dizer, ou se disse sem querer), mas em determinar qual a posição que pode e deve ocupar um indivíduo para ser o seu sujeito" (Agamben, 2008, p. 143). Ocupar a posição de enunciante diante do arquivo de saberes significa, por sua vez, tomar a palavra, tornar-se seu testemunho, estar delimitado pelo dizível e pelo não dizível da língua. Assim, se no arquivo o sujeito é elidido e reduzido a simples função, sendo lançado no rumor anônimo dos enunciados, no testemunho, revela-se sua potência de dizer, revela-se a contingência de seu lugar frente ao próprio fato de ter ou não língua. Isso nos leva a considerar que, do ponto de 
Referimo-nos ao rosto como, nos diz Agamben (1996), a paixão da revelação, que não é qualquer coisa que possa ser formulada nessa ou naquela proposição significante, nem mesmo é um segredo destinado a restar para sempre incomunicável. O rosto, pelo que revela e esconde, sempre emerge como perturbação e vergonha. vista do testemunho, ou seja, entre langue e arquivo, exige-se uma subjetividade como aquilo que atesta, na própria possibilidade de falar, uma impossibilidade da palavra.

A Mostra, reunindo as vozes de tantos provindos de quaisquer lugares, casos e situações, também pode, a nosso ver, erguerse como um grande testemunho daqueles, pesquisadores e profissionais, que falam por aqueles que estão impossibilitados da palavra. Revela-se como memória viva e ativa daquilo em que estamos nos tornando, dos atos que produzimos frente à dureza e às perplexidades de nosso presente. Arquivo e testemunho dizem da direção de nossa política e atestam nossa relação com o outro, com nossa alteridade. Dispõem-se como analisadores de nossas práticas em seu grau de uma coragem de verdade, pela qual somos forçados, pela nossa palavra e pelo nosso ato enunciativo, a restituir ao plano do comum aquela multidão silenciosa que se abriga assujeitada nas dobras dos poderes vigentes. Fazer falar o silêncio, preencher o deserto do real de vozes inaudíveis, pode muito bem tornar-se uma utopia pela qual trabalhamos, insistimos e que reiniciamos a todo o momento. A promoção da Mostra Nacional revela-se, então, como nosso próprio rosto, ultrapassando o semblante representável daquilo que evidenciamos. Vemos, nela, o rosto de nossa psicologia, nosso próprio, sempre suspenso sobre um fio sobre o abismo. O rosto que então podemos ver torna-se aquilo mesmo que já não mais reconhecemos, tornando-se o estranhamento nossa mais insubstancial condição e potência para insistir e prosseguir.

Ao expor nossos trabalhos na grande Mostra, na verdade, trazemos "à aparência a aparência mesma" como nossa tarefa política. Referimonos ao rosto como, nos diz Agamben (1996), a paixão da revelação, que não é qualquer coisa que possa ser formulada nessa ou naquela proposição significante, nem mesmo é um segredo destinado a restar para sempre incomunicável. O rosto, pelo que revela e esconde, sempre emerge como perturbação e vergonha. Sua exposição é o lugar da política, o lugar de uma luta, o lugar de onde podemos fazer História. Assim, na Mostra, como o grande rosto da Psicologia atual, a aparência daquilo que está exposto se torna, ao mesmo tempo, própria e imprópria, possível e real, levando-nos a abraçar a impropriedade, ou seja, aquilo que não nos pertence e que nos faz caminhar obscuramente em sua luz. A Mostra possui um rosto que não encobre a verdade, mas que é um estar-junto de múltiplos semblantes, sem que se tome para isso a sede de uma verdade que signifique semelhança. No rosto da Mostra, deposita-se a simultaneidade dos semblantes, a inquieta potência que os mantém juntos e os reúne.

A Mostra refere-se ao acúmulo de um passado ontológico no qual estamos mergulhados e que nos é colocado a priori. Algo no arquivo se encontra no vazio da linguagem, ocupa o lugar do ainda não ou do quase dito e nos convoca a sondá-lo, precisamente em sua zona cinzenta e escura. Tal sondagem é feita particularmente por uma multidão inquieta e inquietante, desassossegada com o seu tempo presente, potente para também desfazer o já feito e o já visto, em um ato destrutivo que abriga, contudo, a própria possibilidade de construção do presente, multidão tomada por um tempo que lhe é impessoal e que não se refere a um passado que foi deixado para trás e que não pode, eventualmente, ser chamado de volta pela memória, multidão que, ao comemorar este aniversário de nossa ciência e profissão, busca manter-se próxima de uma zona de não conhecimento, a partir da qual compreende que toda verdade é produzida pelas condições de seu tempo, que suas práticas se produzem como efeitos de formações discursivas, multidão que libera suas múltiplas vozes para dar vazão a expressões enunciativas que podem desmantelar aquilo que, diante de nós, brilha como enunciado seguro e verdadeiro. 
As práticas não se desgrudam desse tempo criador e intempestivo que já não cabe na imagem de uma linha reta em direção ao futuro, tempo fora dos trilhos, porta fora dos gonzos que se abre para as multiplicidades, e que, como martelo, estilhaça o duro e frio gelo que envolve o mundo das formas reconhecíveis e representáveis. Tornamo-nos corpos-de-passagem dos relâmpagos desse tempo e passamos a compreender que já não se trata de alinhar datas em presente, passado e futuro. A fórmula historicista fracassa, a contagem dos dias e dos anos já não importa, aqui não há envelhecimento, apenas as potências da infância do pensamento nos movem para que, como bons ladrões, façamos recombinações, novas composições, embaralhemos os códigos a favor de uma vida, de um livro, de uma comunidade por vir. De certa maneira, tornamo-nos habitantes de uma cidade deserta, povoada tão somente de elementos não formados que se prestam, pois, a serem extraídos do solo a que são imanentes para invenções que ajam a contrapelo da História, que atuem contra o tempo presente e, esperemos, a favor de um tempo vindouro.

A intimidade com a zona de nosso não conhecido torna-nos, antes de tudo, testemunhas de que somos mais e menos do que nós mesmos e nos possibilita entender, pois, que, de um lado, participamos de uma vida vivida e já marcada pela experiência, e, de outro, de uma vida rumorosa, nebulosa e por vir que espera nosso agenciamento ativo para existir. Mais do que rememorativos e reprodutores, tornamo-nos aqueles que fazem o trabalho do negativo, que, não significando falta ou carência, aponta o excesso que nos habita, paixão cega e silenciosa, sem limite de tempo e espaço e que nos faz devir-humanos a partir de um não, como nos mostra André Green (2010).

Tornamo-nos sujeitos de um incansável trabalho do negativo, de um trabalho de morte que serve, contudo, para preservar a vida, para preservar e fazer durar a vida, lançando-a para além de seus instantes-pingos incessantes de um tempo que somente passa em um presente vivo. Habitamos, agora, o tempo da duração, alojando-nos não somente naquilo que as condições tornam possível. Mesmo não desconhecendo que precisamos de possíveis para prosseguir e que nossas práticas de liberdade sempre se referem a algo que nos proíbe e cerceia, entendemos também que "o possível é o efeito combinado da realidade, uma vez surgida, e de um dispositivo que a repele para trás" (Bergson, 2006, p.116).

Assim, recomenda-nos o filósofo que devolvamos o possível ao seu lugar, pois a evolução criadora, no sentido bergsoniano que nos interessa, "torna-se algo inteiramente diferente da realização de um programa; as portas do porvir abrem-se de par em par; um campo ilimitado oferece-se para a liberdade" (2006, p. 119). Fazer durar a cidade da Psicologia não significa, pois, mantê-la incólume à presença do estranho-não-familiar. Fazê-la durar, em certa medida, é reconhecer nela potências que excedem aquilo que nela existe e que povoa a sua superfície, podendo ser visível e enunciado. Fazê-la é também partir do ponto de nossa insuficiência para dizê-la e abarcá-la com nossos atos de vontade e consciência.

A cidade assemelha-se a nós: também partilha de luzes e de escuridão, vive o duplo de uma vida cindida entre a História e o acontecimento, vive uma não coincidência com seu próprio presente, sendo, assim inatual. Diacrônicos, nós e a cidade dos psicólogos, vivemos uma singular relação com nosso próprio tempo: aderimos a ele e, ao mesmo tempo, dele tomamos distância. Fixamos nosso olhar nos objetos de nosso interesse para ver-lhes alguma obscuridade, para escrevê-los "mergulhando a pena nas trevas do presente" (Agamben, 2009, p. 
63). Referimo-nos ao escuro não como passividade ou nihilismo, mas exatamente como trabalho a ser feito diante do eterno retorno como o grande teste ético e seletivo da vida pelo qual cada homem tem de passar; referimo-nos, ainda, ao nosso presente não como instante matemático, mas como um real vivido que se ocupa necessariamente de uma duração, pois

o que chamo 'meu presente' estende-se ao mesmo tempo sobre meu passado e sobre o meu futuro. Sobre meu passado em primeiro lugar, pois o momento em que falo já está distante de mim; sobre meu futuro a seguir, pois é sobre o futuro que esse momento está inclinado, é para o futuro que eu tendo (...) (Bergson, 1990, p. 111)

Quando pensamos sobre nosso presente como devendo ser, ele ainda não é, e quando pensamos sobre ele como existente, ele já passou, portanto, não cabe pensar o presente como aquilo que é, mas sim, como aquilo que se faz, que se faz entre aquilo que assume existência e aquilo que ainda resta a existir, que se faz quando não nos deixamos cegar pelas luzes do século e conseguimos adentrar sua íntima obscuridade, que se faz quando percebemos o escuro de nosso tempo como algo que nos concerne e que não cessa de nos interpelar. Ser contemporâneo ao presente corresponde, portanto, segundo Agamben (2009, p. 64), àquele "que recebe em pleno rosto o facho de trevas que provêm do seu tempo".

Manter-se no ponto de fratura, ali, onde as vértebras do século se mostram quebradas, situar-se no tempo intempestivo, íntimo de suas urgências e transformações, posicionarse como anacrônicos, condição que nos permite apreender o nosso presente na forma de um muito cedo que é, também, um muito tarde, de um já que é, também, um ainda não, viajar no tempo sabendo que sua luz é inalcançável. A Mostra Nacional de Práticas em Psicologia revela-se, a nosso ver, não como suporte para um tratado moral à nossa contemporaneidade. Está regida pela ética e distante deve se situar de uma lista de prescrições e intimidações; refere-se, sobretudo, ao plano comum de uma comunidade que, não estando regida pela semelhança, trata, contudo, de expressar-se através de estilos derivados de seu engajamento intelectual, plano comum de coexistências de estilos que, não sendo inocentes, revelam, sobretudo, os modos que produzimos para afrontar a insuficiência de nossas percepções e de nossa memória, ou seja, fala dos graus de potência que investimos na transformação do mundo e dos homens, e não apenas em sua reificação identitária.

\section{Os diálogos da Psicologia com outros saberes}

Recuamos, aqui, mais uma vez, da posição de historicizar. O ponto, ou melhor, o punctum de nossa observação, isto é, aquele em que buscamos reunir as forças que podem nos levar a uma ideia, nos conduz a que renunciemos, no momento, ao inventário de diálogos e de influências da Psicologia com outros saberes, uma vez sabermos que, desde os seus primórdios, nossa ciência tem se nutrido de noções de outros domínios científicos e filosóficos, a partir dos quais se reenquadra em território específico e próprio.

Da mesma forma, não deixamos de lembrar que, para tornar-se ciência, a Psicologia desmembrou-se da Filosofia, marcando seu corpus conceitual e metodológico com critérios racionalistas e funcionalistas, vigentes à época positivista, com vistas a obter sua legitimação e reconhecimento científico. Fundou, dessa maneira, um tipo de homem que, como seu objeto, passou a poder ser mensurado, sendo dotado de consciência e vontade e, em consequência, acessível como objeto de previsão e controle. Nessa fundação, a própria ciência voltada para 
o estudo do homem desprezou as suas propriedades inconscientes e irracionais, fazendo-lhe predominar a voz da consciência e uma vontade positivas. Adaptável, previsível e mensurável, o homem então inventado tornou-se explicável somente por aquilo que deixava transparecer como comportamento.

Suas motivações inconscientes, sua tendência ao infinito e mesmo sua dimensão espiritual não foram consideradas, contudo, não desapareceram. O homem psicológico criado pela grelha da razão positiva e funcionalista deixou dívidas em relação ao real do homem, aquele do vitalismo, que reúne em si o humano e o inumano, o material e o imaterial, o finito e o ilimitado ao mesmo tempo. O caos, para a ciência de então, foi recusado como parte integrante da vida e da natureza. As explicações científicas da Psicologia seriam, por fim, colocadas a serviço da moral meritocrática, individualista e classificatória, conduzindo a ciência psicológica a se tornar parte ativa daquilo que Foucault chamou de ortopedia moral, em Vigiar e Punir.

A partir desse momento de legitimação, nossa ciência separou, no homem, aquilo que não pode ser separado, ficando o mesmo à mercê de uma transcendência platônica que reduz a existência dos corpos mortais a um plano secundário e inferior. As operações da alma deveriam, agora sim, comandar os processos sensíveis do corpo então colocados sob a égide de uma razão reta e colocada em função de uma teleologia moralizante. Docilizados pela razão, os homens viramse, pela Psicologia, como objetos a serem corrigidos, apenas simples cópias de ideais supremos e puros transcendentes a eles. Comparável e manipulada sempre com valores colocados nas alturas, a existência humana foi esquartejada em seu conatus e desviada para atender os interesses sociais, econômicos e morais de seu tempo.
O homem tornou-se, assim, doente de uma história que, ao buscar salvá-lo das perdições de um corpo capaz de acolher o erro e as ilusões, também tornou-o culpado e devedor individualizado pelo que não podia cumprir das promessas que sua herança social the imputara. Assim, demarcamos, nesta breve passagem, que o estatuto científico aspirado e conquistado pela Psicologia centrou-se, sobretudo, nessa impossibilidade de ela acolher o homem em toda a sua natureza incerta, tornando-o psicológico e fruto interiorizado de ideias universais e abstratas.

Em O que é a Filosofia?, Deleuze e Guattari, ao examinarem a questão científica, dizemnos que os atos fundamentais da faculdade científica de conhecer expressam-se nas seguintes direções:

colocar limites que marcam uma renúncia às velocidades infinitas, e traçam um plano de referência, determinar variáveis que se organizam em séries tendendo no sentido desses limites, coordenar as variáveis independentes, de modo a estabelecer, entre elas ou seus limites, relações necessárias das quais dependem funções distintas, o plano de referência sendo uma coordenação em ato, determinar as misturas ou estados de coisas que se relacionam com as coordenadas e às quais as funções se referem" (1992, p. 275)

Entretanto, como apontam os autores franceses, as operações da cognição humana ainda insistem em suas relações com o caos, cabendo à ciência atual colocá-lo em evidência, posto que o próprio cérebro, como sujeito do conhecimento, nele se encontra mergulhado. Podemos, assim, perceber que, se considerarmos o próprio cérebro como o sujeito do conhecimento, entendendo que não é o homem que pensa, mas sim, seu cérebro, faremos uma viragem de um paradigma arborizado para outro rizomático, composto de sistemas acentrados e redes de autômatos infinitos. "É o cérebro que diz Eu, mas Eu é um outro" , dizem-nos os autores de O que é a Filosofia? (1992, p. 271). A sensação não é menos cérebro que o conceito. 
Trabalho essencialmente humano, as ciências são propostas, por Deleuze e Guattari, junto às artes e à Filosofia, como armas que venham rasgar aquele guarda-sol de opiniões fáceis

que construímos frente à nossa necessidade de um pouco de ordem para nos proteger do caos. "O filósofo, o cientista, o artista parecem retornar do país dos mortos" (1992, p. 260).
O cérebro opera por ressonâncias entre matérias heterogêneas dispostas a conectarse sem uma direção externa que as conduza, funciona por interferências extrínsecas e intrínsecas, por deslizamentos sutis que introduzem sensibilidade na ciência. Também existem as interferências ilocalizáveis que colocam cada disciplina em relação com o negativo: mesmo a ciência está em relação com uma não ciência, que lhe devolve efeitos. Não se trata, desse ponto de vista, de dizer somente que a arte deve formarnos, despertar-nos para o sentir, e que a Filosofia deve ensinar-nos a conceber, e a ciência, a conhecer. Isso seria considerar Arte, Filosofia e Ciência de um ponto puramente efetuado e positivo, elidindo a relação que as mesmas possuem com o Não que a elas concerne. Filosofia e Não Filosofia, Arte e Não Arte, Ciência e Não Ciência emergem como relações de cada um dos domínios com seu FORA, com aquilo que ainda resta dizer, em sua própria linguagem, com aquilo que ainda resta extrair com seu próprio método e técnica. No cérebro, tais relações não se distinguem. Ali, tudo funciona por interferências caóticas, sendo essas as operações que podemos chamar de pensamento, extraído do caos, pensamento não racionalizado compartilhado como sombra que não cessa de acompanhar os três domínios - das sensações, dos conceitos e das funções.

Buscamos colocar, aqui, a distinção entre pensamento e razão, faces imanentes ao humano em que nos tornamos, e, da mesma forma, buscamos posicionar a Psicologia como ciência em intimidade com a sua face de não ciência que, como seu duplo íntimo, poderia ser chamada também de escuro, de indizível, invisível e inaudível, tal como mencionávamos na seção anterior. Trabalho essencialmente humano, as ciências são propostas, por Deleuze e Guattari, junto às artes e à Filosofia, como armas que venham rasgar aquele guarda-sol de opiniões fáceis que construímos frente à nossa necessidade de um pouco de ordem para nos proteger do caos. "O filósofo, o cientista, o artista parecem retornar do país dos mortos" (1992, p. 260). O primeiro traz do caos as variações que permanecem infinitas e que, no entanto, são tornadas inseparáveis em reencadeamentos conceituais; o segundo traz do caos variáveis, tornadas independentes por desaceleração, e que, uma vez retidas, entram em relações determináveis em uma função; por último, o artista traz do caos as variedades, que não constituem mais uma reprodução sensível, erigindo um ser do sensível, capaz de restituir o infinito. Trata-se de vencer o caos, de passar pela fissura, de dar um salto, de arriscar-se a ser arrastado em pleno mar; trata-se de uma amizade com o inimigo, de abrir fendas nos véus que cegam nosso olhar.

Ciência, Filosofia e arte buscam aproximarse o quanto podem das vagas tempestuosas do caos, e, cada qual a seu modo, com seus métodos, realiza a criação do mundo voltando-se contra tudo aquilo que quer dá-lo como explicado e transparente. O caos torna-se aqui aquele imenso negativo que é afirmado como trabalho do cérebro humano.

Estar no caos, expressar suas forças através de estratégias que busquem resolver as tensões entre elas, significa torcer a recognição para a criação, tornando-se mais relevante o modo como colocamos os problemas e não o modo como procuramos solucioná-los. Se, para cada domínio do saber, existe seu negativo, também podemos considerar o negativo do próprio homem, uma vez que ao homem colocado pelos padrões racionalistas 
e funcionalistas confronta-se o outro do homem, inextrincavelmente ligado a ele em complicadas sínteses disjuntivas. Ir além do homem significaria sondar e liberar o homem que foi deixado de fora pela grelha cientificista, operação que poderíamos ver como dotada da coragem de verdade e do enfrentamento à vergonha de ser homem.

Talvez tenha sido esse um dos importantes alertas que nos é dado por filósofos como
Nietzsche, Foucault, Deleuze e Guattari, Simondon, Bergson e Spinoza, que, juntamente a outros notáveis artistas e cientistas, fazem reviravoltas no solo da cidade dos homens para desenterrá-los. 


\section{Tania Mara Galli Fonseca}

Pós-doutorado pela Universidade de Lisboa. Professor Titular da Universidade Federal do Rio Grande do Sul, Rio Grande do Sul, RS - Brasil.

E-mail: tfonseca@via-rs.net

\section{Endereço para envio de correspondência:}

Rua Campos Salles, 262, Bairro Boa Vista, Porto Alegre, Rio Grande do Sul - RS - Brasil. CEP: 90480-030.

Agamben, Giorgio. (1996). Il volto. In Note sulla política (pp. 74-80). Torino: Bollati Boringhieri.

Agamben, G. (2008). O que resta de Auschwitz: o arquivo e o testemunho. São Paulo: Boitempo.

Agamben, G. (2009). O que é o contemporâneo? e outros ensaios. Chapecó, SC: Argos.

Bergson, H. (1990). Matéria e memória. Ensaio sobre a relação do corpo com o espírito. São Paulo: Martins Fontes.

Bergson, H. (2006). O pensamento e o movente. São Paulo: Martins Fontes.
Deleuze, G. (1998). Foucault. São Paulo: Brasiliense.

Deleuze, G., \& Guattari, F. (1992). O que é a filosofia? Rio de Janeiro: Editora 34.

Green, A. (2010). O trabalho do negativo. São Paulo: Artmed.

Nietzsche, F. (2003). Segunda consideração intempestiva. Da utilidade e desvantagem da história para a vida. Rio de Janeiro: Relume-Dumará. 